\title{
Impaired Hepatic Glycogenolysis Related to Hyperinsulinemia in Newborns from Hyperglycemic Pregnant Rats
}

\author{
P. JAME, A. KTORZA, M. T. BIHOREAU, N. NURJHAN, P. FERRÉ, J. GIRARD, AND L. PICON \\ Laboratoire de Physiologie du Développement, URA CNRS 307, Université Paris 7, 75251-Paris Cedex 05, \\ Paris, France [P.J., A.K., M.T.B., N.N., L.P.] and Centre de Recherches sur la Nutrition, \\ 92190-Meudon-Bellevue, France [P.F., J.G.]
}

\begin{abstract}
We have investigated the respective roles of insulin and glucagon in the initiation of hepatic glycogen degradation during the early postnatal period in rats, with special regard on the inhibitory effect of insulin on this process. Pregnant rats were rendered either slightly $(8.5$ $\mathrm{mM}$ ) or highly hyperglycemic $(22 \mathrm{mM})$ by infusing glucose during the last week of pregnancy. Fasted, newborn rats were studied from delivery to $16 \mathrm{~h}$ postpartum. At birth, newborns from slightly hyperglycemic rats showed higher glycemia and insulinemia and lower plasma glucagonemia compared with controls. Newborns from highly hyperglycemic rats were still more hyperglycemic and exhibited low plasma glucagon concentrations, but they were not hyperinsulinemic. In control newborns, hepatic glycogen breakdown was triggered by $2 \mathrm{~h}$ after delivery. By contrast, hyperglycemic-hyperinsulinemic newborns (newborns from slightly hyperglycemic rats) were unable to mobilize liver glycogen before 8-10 h after delivery. In hyperglycemicnormoinsulinemic newborns (newborns from highly hyperglycemic rats), hepatic glycogen concentration significantly started to decline $2 \mathrm{~h}$ after delivery and was no longer different from controls at $8 \mathrm{~h}$. Anti-insulin serum injection at delivery promoted a prompt decrease in liver glycogen stores in controls as well as in newborns from slightly hyperglycemic rats. Phosphorylase a/synthase a ratio rose rapidly after delivery in controls and in newborns from highly hyperglycemic rats (maximum $4 \mathrm{~h}$ ), whereas in newborns from slightly hyperglycemic rats, it rose much more slowly than in the two other groups (maximum 16 h). These data suggest that, in newborns from hyperglycemic mothers, hyperinsulinemia during late fetal and early neonatal life is the main factor preventing postnatal hepatic glycogenolysis. (Pediatr Res 28: 646-651, 1990)
\end{abstract}

\section{Abbreviations}

SH, slightly hyperglycemic $\mathrm{HH}$, highly hyperglycemic IRI, immunoreactive insulin IRG, immunoreactive glucagon

Because of the abrupt interruption of maternal glucose supply at birth, rapid adaptative changes are required to maintain

Received February 26, 1990; accepted July 10, 1990.

Correspondence and reprint requests: A. Ktorza, Laboratoire de Physiologie du Développement, URA CNRS 307, Université Paris 7, 2 Place Jussieu; Tour 23-33, ler étage, 75251-Paris Cedex 05.

Supported in part by a grant from the Institut de la Santé et de la Recherche Médicale (INSERM) (Grant no. 857010). glucose homeostasis in newborn mammals. The breakdown of the large glycogen stores that have been accumulated in the fetal liver during late pregnancy represents the more rapidly available endogenous source of glucose $(1,2)$.

Hepatic glycogen metabolism is primarily controlled by the respective concentrations of insulin and glucagon in the plasma (3), and it could be assumed that even a slight change in the secretion of one or both hormones during the fetal life may hamper the metabolic adaptation of the newborn to extrauterine life. This is suggested by the situation of infants of poorly controlled diabetic women in whom the severe postnatal hypoglycemia is mainly due to defective glucose production (4).

We have previously shown that newborn rats of dams rendered slightly hyperglycemic by continuous glucose infusion during the last third of pregnancy were hyperglycemic at birth, but were profoundly hypoglycemic in the early postnatal period. This hypoglycemia seemed to be due, in a major part, to a defective postnatal hepatic glycogen breakdown, in contrast to control newborns, which exhibited sustained postnatal hepatic glycogenolysis (5). Concurrently, in newborns from hyperglycemic rats, the insulin/glucagon molar ratio was much higher than in control newborns, suggesting that impaired postnatal liver glycogenolysis could be related to an abnormal secretion of the two pancreatic hormones during the perinatal period.

Using the same experimental model, we have investigated in our study the respective roles of insulin and glucagon in liver glycogen breakdown triggering, focussing on the possible inhibitory effect of hyperinsulinemia on this process.

For this purpose, two experimental approaches have been used. 1) Postnatal hepatic glycogenolysis was investigated in newborns from pregnant rats rendered either slightly hyperglycemic to induce hyperinsulinemia in the fetus at term, or highly hyperglycemic to obtain fetal hyperglycemia without hyperinsulinemia. Indeed, it has been previously reported by us and by others that fetuses from moderately hyperglycemic pregnant rats were hyperinsulinemic at term $(6,7)$, whereas fetuses from severely hyperglycemic rats were either normoinsulinemic $(7,8)$ or hypoinsulinemic (6). 2) The effect of anti-insulin serum injection on liver glycogen concentration in newborn rats from slightly hyperglycemic and control pregnant rats was examined.

\section{MATERIALS AND METHODS}

Animals. Albino rats from the Wistar strain fed ad libitum a standard diet (UAR 113) were used. Three-mo-old virgin females weighing about $250 \mathrm{~g}$ were caged with one male for one night $(1700$ to $0900 \mathrm{~h}$ ) and pregnancy was detected by abdominal palpation $13 \mathrm{~d}$ later.

Dams were rendered hyperglycemic during the last third of pregnancy by continuous glucose infusion under unrestrained conditions as described previously (9), according to the technique 
of Nicolaïdis et al. (10). On d 13 of pregnancy, they were operated on. The infusion started on d 15 of pregnancy and lasted until delivery. Hypertonic (30\% wt/vol) sterile glucose (Chaix \& Dumarais, Paris, France) was infused either at the initial rate of 30 $\mu \mathrm{L} / \mathrm{min}$ to produce slight hyperglycemia ( $\mathrm{SH}$ rats) or at the rate of $50 \mu \mathrm{L} / \mathrm{min}$ to obtain high hyperglycemia ( $\mathrm{HH}$ rats). When necessary, initial infusion rates were modified during the infusion period to maintain glycemia in the desired ranges. Control rats were infused with a glucose-free solution. Blood glucose levels fluctuated between 8.5 and $11 \mathrm{mM}$ in slightly hyperglycemic dams and between 22 and $28 \mathrm{mM}$ in highly hyperglycemic pregnant rats. Rats in which glycemia did not stay in these ranges were discarded.

Because precise timing of birth and sampling was wanted, newborns were obtained by cesarean section on $\mathrm{d} 21.5$ of pregnancy (duration of pregnancy $22 \mathrm{~d} \pm 6 \mathrm{~h}$ ) after cervical dislocation of the mother. Two newborns of each litter were immediately killed after sampling and the remaining newborns were transferred to an incubator in a humid atmosphere (relative humidity at $70 \%$; Memmert, Schwabach, FRG) and maintained at $37^{\circ} \mathrm{C}$. Newborns from a given litter were studied in a sequential way-two newborns were killed every $2 \mathrm{~h}$-so that each data point is the mean of values from different litters. For newborns of highly hyperglycemic dams, the hormonal study was limited to the 6 postnatal $h$.

Some newborns from control and glucose-infused dams were injected intraperitoneally just after delivery with $100 \mu \mathrm{L}$ of either $1 / 1000$ diluted guinea pig anti-insulin serum or normal guinea pig serum. One hundred $\mu \mathrm{L}$ of the diluted anti-insulin serum had an insulin neutralizing capacity of $6 \mathrm{nM}$. Newborns were killed $2 \mathrm{~h}$ after this treatment.

Blood samples. Plasma glucose of infused pregnant rats was measured twice daily using a semiquantitative method (Haemoglukotest; Boehringer, Mannheim, FRG) on blood samples collected from the tail vein.

In newborns, blood samples were collected sequentially from the axillary vessels in microtubes cooled in ice water. They were centrifuged and the plasma was separated. Glycemia was determined on a $10-\mu \mathrm{L}$ aliquot and the remainder of the sample was kept at $-20^{\circ} \mathrm{C}$ until RIA for insulin and glucagon. Upon completion of blood collection (at most, $30 \mathrm{~s}$ ), the liver was rapidly removed, weighed, and cut up into three pieces that were frozen in liquid nitrogen for glycogen, glycogen synthase, and glycogen phosphorylase determinations.

Biochemical methods. Plasma glucose was determined by the glucose-oxidase technique with a glucose analyzer (Beckman, Palo Alto, CA).

Plasma IRI was estimated using purified rat insulin as standard (R-171-Novo, Copenhagen, Denmark), an antibody to a mixture of porcine and bovine insulin, monoiodinated ${ }^{125} \mathrm{I}$-insulin. Charcoal was used to separate free from bound hormone. The lower limit of the assay was $35 \mathrm{pM}$ with a coefficient of variation within and between assays of $10 \%$.

Plasma IRG was measured on unextracted samples using porcine monoiodinated ${ }^{125} \mathrm{I}$-glucagon as tracer, and a charcoaldextran technique. The coefficients of variation were the same as for plasma IRI determination.

Liver glycogen concentration was determined by the amyloglucosidase technique of Roehrig and Allred (11) and was expressed as $\mathrm{mg} / \mathrm{g}$ of liver.

Glycogen synthase (EC 2.4.1.11) and glycogen phosphorylase (EC 2.4.1.1) activities were measured according to the methods of Hue et al. (12) and Stalmans et al. (13), respectively, which allow one to measure separately glycogen synthase a and glycogen synthase $\mathrm{a}+\mathrm{b}$ on one hand and glycogen phosphorylase a and glycogen phosphorylase $a+b$ on the other.

Results are expressed as means \pm SEM. Significance of differences between means were evaluated by a two-way analysis of variance.

\section{RESULTS}

Effect of glucose infusion on pregnant rats. Hyperglycemia was maintained in pregnant rats throughout the period of infusion with glucose. As determined by the semiquantitative method, three groups could clearly be distinguished: 1 ) rats infused with the glucose-free solution (controls), the glycemia of which was between 4.5 and $5.5 \mathrm{mM}$; 2) rats infused with glucose at a low rate $(\mathrm{SH})$, which exhibited a glycemia between 8.5 and $11 \mathrm{mM}$; and 3 ) rats infused with glucose at a high rate $(\mathrm{HH})$, which were markedly hyperglycemic (between 22 and $28 \mathrm{mM}$ ). This was confirmed by the plasma glucose concentration precisely measured in the pregnant rats before removal of the fetuses $(4.55 \pm$ $0.16 \mathrm{mM}, n=20$ for controls; $9.52 \pm 0.45 \mathrm{mM}, n=17$ for $\mathrm{SH}$ rats; $24.42 \pm 0.67 \mathrm{mM}, n=16$ for $\mathrm{HH}$ rats). The differences between the three groups were highly significant $(p<0.001)$.

Hyperglycemia was related to high plasma insulin concentrations $(2754 \pm 252 \mathrm{pM}, n=17$ for SH rats; $5376 \pm 362 \mathrm{pM}, n=$ 16 for $\mathrm{HH}$ rats) compared with control rats $(558 \pm 54 \mathrm{pM}, n=$ 20). All the differences were significant.

Effect of Gestational Hyperglycemia on Glucose Metabolism in Newborns. Perinatal mortality. No difference between the three groups was observed in the frequency of stillbirths (controls: $10.5 \%, n=60$; newborns from SH rats: $11 \%, n=70$; newborns from $\mathrm{HH}$ rats: $12.5 \%, n=55$ ). During the first $2 \mathrm{~h}$ after birth, the mortality was increased 2-fold in newborns from SH mothers (11\%) compared with controls $(4.5 \%)$ and newborns from $\mathrm{HH}$ mothers $(5 \%)$. Beyond that period, all newborns survived.

Plasma glucose levels. Maternal hyperglycemia was reflected in the plasma glucose concentration of the newborns. At birth, plasma glucose level was significantly higher in newborns from $\mathrm{SH}$ rats than in controls and was significantly increased in newborns from $\mathrm{HH}$ rats compared with the two other groups (Fig. 1). In the three groups of newborns, glycemia fell rapidly after birth over the first $2 \mathrm{~h}$. This decrease led to severe hypoglycemia in newborns from $\mathrm{SH}$ rats and, to a lesser extent, in control newborns, but not in newborns from $\mathrm{HH}$ rats, which remained hyperglycemic $2 \mathrm{~h}$ after birth. Afterwards, glycemia rose in controls and in newborns from $\mathrm{SH}$ rats and decreased in newborns from $\mathrm{HH}$ rats to reach normal values at $6 \mathrm{~h}$. It remained stable until $16 \mathrm{~h}$ in newborns from SH rats, whereas it strikingly decreased in the other two groups (Fig. 1).

Plasma hormone concentrations. At delivery, plasma IRI was 2-fold increased in newborns from SH mothers, as compared with controls, whereas it was not significantly increased in newborns from $\mathrm{HH}$ rats, despite marked hyperglycemia. Insulinemia dramatically fell over the first $2 \mathrm{~h}$ and onward in all newborns. However, it remained higher in newborns from $\mathrm{SH}$ mothers than in controls at 2 and $4 \mathrm{~h}$ after birth (Fig. 2).

At delivery, plasma IRG was much lower in newborns from $\mathrm{SH}$ and $\mathrm{HH}$ rats than in controls. It increased acutely immediately after birth in controls and then decreased between 30 min and $6 \mathrm{~h}$. In newborns from $\mathrm{SH}$ rats, the postnatal surge of glucagon was attenuated compared with that in controls, but it evolved similarly until $6 \mathrm{~h}$. Thereafter, plasma glucagon concentration increased until $16 \mathrm{~h}$, slightly in newborns from $\mathrm{SH}$ mothers and strongly in controls. The difference between both groups was highly significant $(p<0.001)$. The immediate postnatal surge of glucagon was abolished in newborns from $\mathrm{HH}$ mothers, in which the concentration of the hormone slightly increased between 2 and $6 \mathrm{~h}$ (Fig. 3). Thus, the newborns from $\mathrm{HH}$ rats were characterized during the $6 \mathrm{~h}$ after delivery by a near normal time course of insulinemia with rather low glucagon concentration. The determination of plasma IRI and IRG concentrations was limited to the first 6 postnatal $h$ in these newborns because the postnatal time course of both hormones and glycogen content was similar in controls and newborns from $\mathrm{HH}$ rats, so that data on insulinemia and glucagonemia after $6 \mathrm{~h}$ in the latter group would not provide further information about 

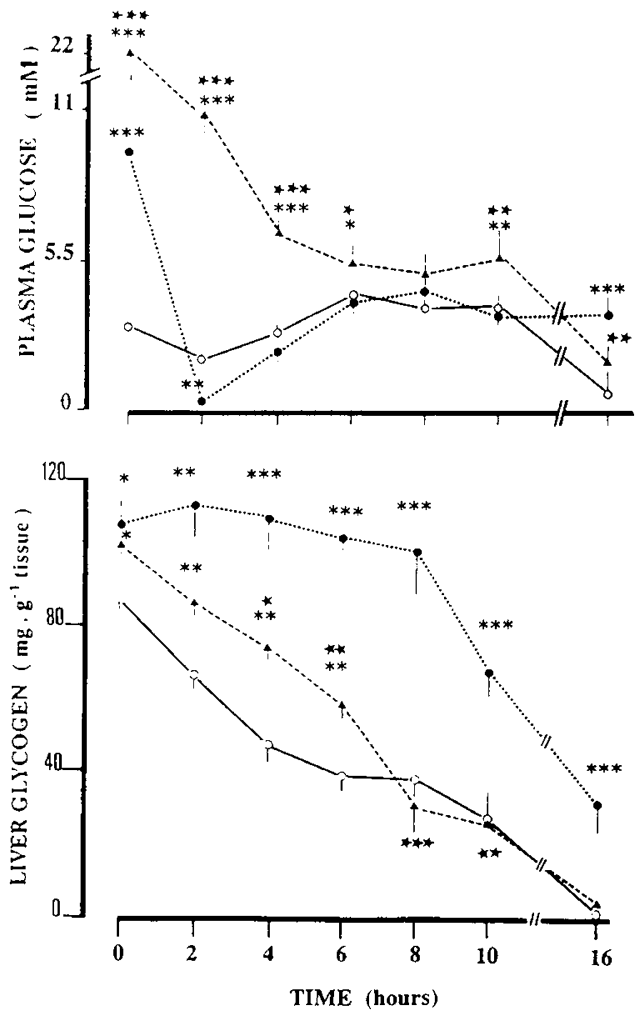

Fig. 1. Time course of plasma glucose (upper panel) and liver glycogen (lower panel) concentrations in control newborns $(O)$, newborns from slightly hyperglycemic rats (๑), and newborns from highly hyperglycemic rats $(\boldsymbol{\Lambda})$. Each data point represents the mean \pm SEM of $20-25$ observations. ${ }^{* * *} p<0.001 ;{ }^{* *} p<0.01 ;{ }^{*} p<0.05$, significantly different from controls. $\star \star \star p<0.001 ; \star \star p<0.01 ; \star p<0.05$, significant difference between newborns from $\mathrm{SH}$ rats and newborns from $\mathrm{HH}$ rats.

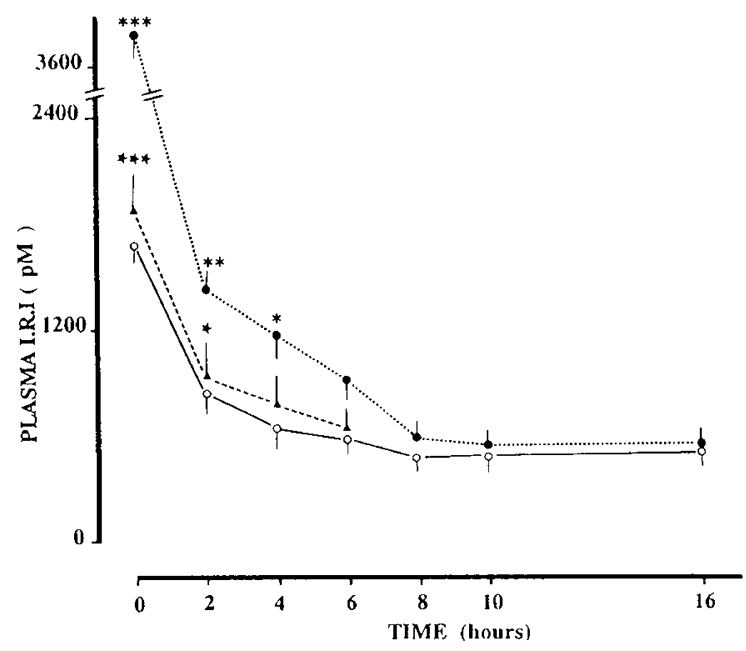

Fig. 2. Plasma insulin evolution in control newborns $(\mathrm{O})$, newborns from SH rats $(\bullet)$, and newborns from $\mathrm{HH}$ rats $(\boldsymbol{\Delta})$. The values are the mean \pm SEM of $40-50$ observations. ${ }^{* * *} p<0.001$; $^{* *} p<0.01 ;{ }^{*} p<$ 0.05 , significantly different from controls. $\star \star \star p<0.001 ; \star p<0.05$, significant difference between newborns from $\mathrm{SH}$ rats and newborns from $\mathrm{HH}$ rats.

the effect of hyperinsulinemia on the impairment of postnatal hepatic glycogen breakdown.

Hepatic glycogen concentration. At delivery, liver glycogen concentration was higher in newborns from $\mathrm{SH}$ and $\mathrm{HH}$ rats than in controls. After birth, it decreased dramatically in controls. It was reduced by $50 \%$ of the initial content at $6 \mathrm{~h}$ and it was almost completely exhausted at $16 \mathrm{~h}$. The situation was strikingly

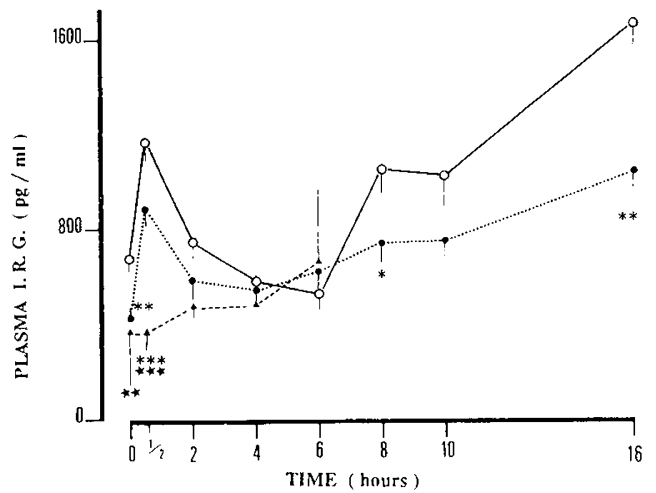

Fig. 3. Plasma glucagon evolution in control newborns $(\mathrm{O})$, newborns from $\mathrm{SH}$ rats $(\boldsymbol{\bullet})$ and newborns from $\mathrm{HH}$ rats $(\boldsymbol{\Lambda})$. The values are the mean \pm SEM of $15-20$ observations. ${ }^{* * *} p<0.001 ; * * p<0.01 ; * p<$ 0.05 , significantly different from controls. $\star \star \star p<0.001 ; \star \star p<0.01$, significant difference between newborns from $\mathrm{SH}$ rats and newborns from $\mathrm{HH}$ rats.

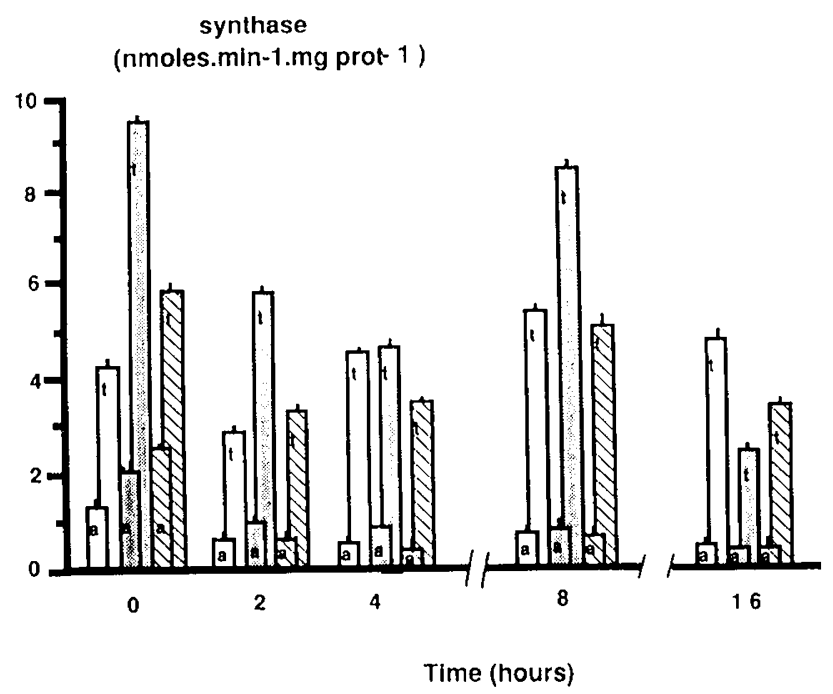

Fig. 4. Glycogen synthase a and total glycogen synthase activities from delivery to $16 \mathrm{~h}$ postpartum in control newborns $(\square)$, newborns

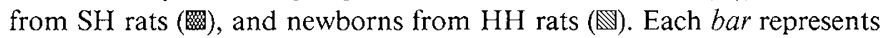
the mean \pm SEM of $10-15$ observations. $a$, glycogen synthase a; $t$, glycogen synthase $a+b$.

different in newborns from $\mathrm{SH}$ rats. Hepatic glycogen did not fall during the first 8 postnatal h, and at $16 \mathrm{~h}$, its concentration still represented about $30 \%$ of the initial value. In newborns from $\mathrm{HH}$ rats, hepatic glycogen concentration regularly decreased after birth, but remained higher than in controls until 6 $\mathrm{h}$. Thereafter, no significant difference persisted with the control group (Fig. 1).

Glycogen synthase activity. In all groups of newborns, glycogen synthase a activity was already very low at birth and decreased over the postnatal period (Fig. 4). Therefore, glycogen synthase was essentially in its inactive form from delivery to $16 \mathrm{~h}$ postpartum in control newborns as well as in newborns of hyperglycemic rats.

Glycogen phosphorylase activity. In control newborns, total glycogen phosphorylase activity slightly increased $2 \mathrm{~h}$ after delivery and then did not change afterwards. In the three groups of newborns, glycogen phosphorylase was essentially in its active form. In controls, phosphorylase a activity rose more rapidly than in newborns from $\mathrm{HH}$ rats and still more than in newborns from SH rats. It decreased between 4 and $16 \mathrm{~h}$. A similar pattern was observed in newborns from $\mathrm{HH}$ rats. In newborns from $\mathrm{SH}$ rats, the time course of phosphorylase activity was different from the two other groups. It did not significantly increase at $2 \mathrm{~h}$ after 
delivery and remained lower than in newborns from control and $\mathrm{HH}$ rats during the early postnatal period. Afterwards, it increased continuously to its maximum at $16 \mathrm{~h}$, i.e. at a time when it was minimal in the other two groups (Fig. 5).

Finally, the phosphorylase a/synthase a ratio was low at delivery in all groups of newborns, although at this time phosphorylase activity was already much higher than synthase activity (Fig. 6). It rose rapidly until $4 \mathrm{~h}$ in controls and in newborns from $\mathrm{HH}$ rats. Afterwards, it decreased to a low at $16 \mathrm{~h}$. In newborns from $\mathrm{SH}$ rats, it rose much more slowly than in the other two groups, but was very high at $16 \mathrm{~h}$.

Effect of anti-insulin serum injection on plasma glucose and liver glycogen concentrations. Newborn rats from control and $\mathrm{SH}$ rats injected with control guinea pig serum showed no significant difference at $2 \mathrm{~h}$ after birth in liver glycogen concentration compared with untreated newborns from control and SH mothers, respectively. By contrast, injection of anti-insulin serum immediately after delivery produced a significant fall in liver glycogen concentration at $2 \mathrm{~h}$ in control newborns as well as in

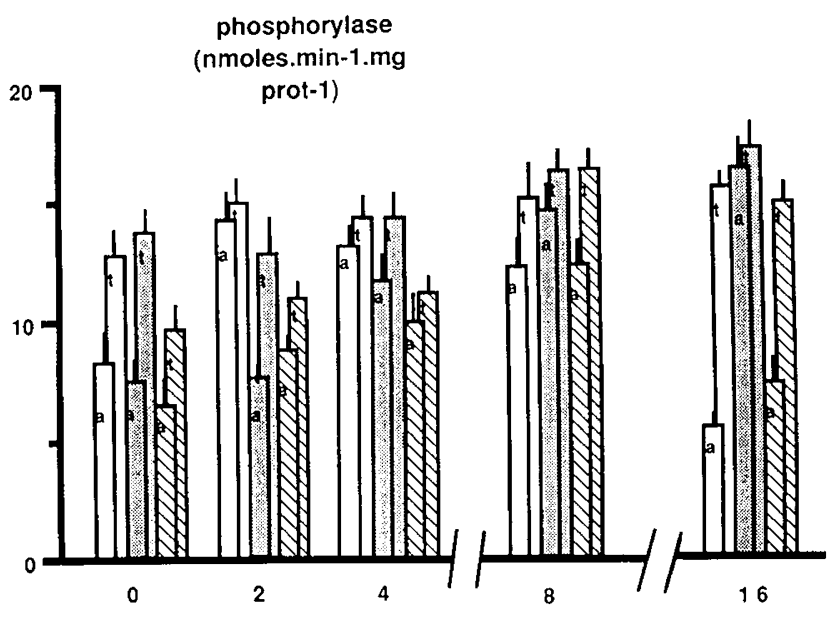

Time (hours)

Fig. 5. Glycogen phosphorylase a and total glycogen phosphorylase activities from delivery to $16 \mathrm{~h}$ postpartum in control newborns $(\square)$,

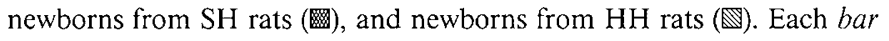
represents the mean \pm SEM of $10-15$ observations. $a$, glycogen phosphorylase $\mathrm{a} ; t$, glycogen phosphorylase $\mathrm{a}+\mathrm{b}$.

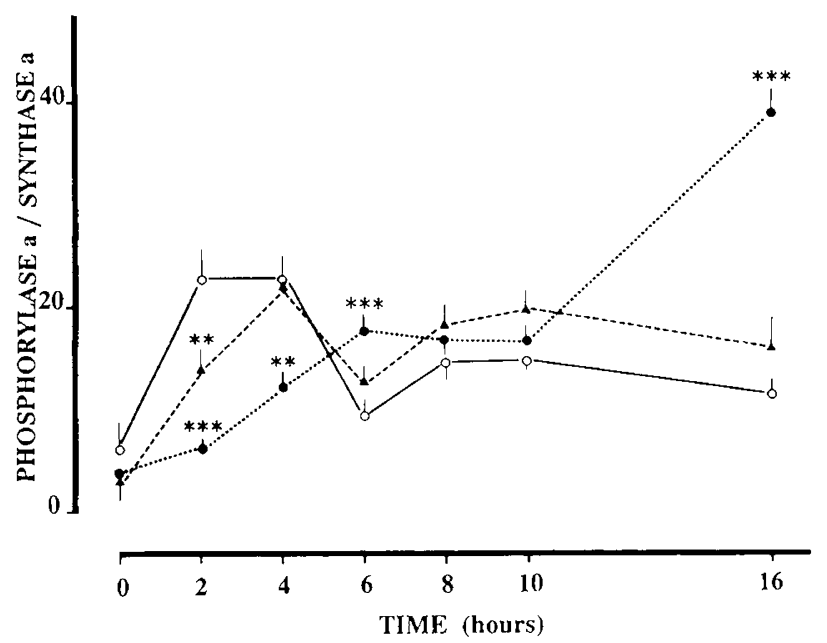

Fig. 6. Glycogen phosphorylase a/glycogen synthase a ratio from delivery to $16 \mathrm{~h}$ postpartum in control newborns $(O)$, newborns from $\mathrm{SH}$ rats $(\bullet)$, and newborns from $\mathrm{HH}$ rats $(\boldsymbol{\Lambda})$. The values are the mean \pm SEM of $15-20$ observations. ${ }^{* * *} p<0.001 ;{ }^{* *} p<0.01$; $^{*} p<0.05$, significantly different from controls. newborns from SH rats. In both groups of anti-insulin seruminjected newborns, liver glycogen concentration was similar at $2 \mathrm{~h}$.

In both groups of newborn rats injected with anti-insulin serum, the decrease in liver glycogen concentration at $2 \mathrm{~h}$ corresponded to an increase in plasma glucose concentration when compared with untreated newborns (Table 1).

\section{DISCUSSION}

Time course of plasma pancreatic hormone concentration after delivery. According to its magnitude, gestational hyperglycemia had quite different effects on plasma insulin concentrations in the newborns. Compared with controls, newborns from $\mathrm{SH}$ rats developed marked hyperinsulinemia, in agreement with many other reports demonstrating hyperinsulinemia in full-term fetuses from either mildly diabetic mothers (reviewed in 14) or slightly hyperglycemic mothers $(7,17)$. By contrast, high gestational hyperglycemia failed to increase plasma insulin concentration in the newborn rats. This confirms our previous studies (5, 7) and is in agreement with the results obtained by others, i.e. when maternal diabetes was severe, plasma insulin levels in term fetuses have been reported to be unchanged (8) or decreased (6) compared with those in controls.

A relationship could be observed between plasma glucose and plasma glucagon concentrations. Plasma glucagon was very low at delivery in both groups of hyperglycemic newborns. Moreover, $30 \mathrm{~min}$ after birth, it increased to a lesser extent in newborns from $\mathrm{SH}$ mothers and did not increase at all in newborns from HH mothers when compared with controls. It is noteworthy that in newborns from $\mathrm{HH}$ rats, plasma glucagon rose progressively from 30 min to $6 \mathrm{~h}$ after delivery concomitantly with the decrease of plasma glucose concentration. These data confirm that the A cell of the endocrine pancreas is sensitive to chronic variations of plasma glucose concentration during the fetal and postnatal periods in agreement with our previous studies $(5,9)$. It is also in accordance with clinical data showing impaired glucagon secretion in newborns from diabetic mothers (15-17).

Plasma glucose and hepatic glycogen concentrations. High plasma insulin and low plasma glucagon levels were observed at delivery and during the very early postnatal period in newborns from SH rats. This is consistent with the postnatal fall of plasma glucose concentration. Nevertheless, hypoglycemia was corrected by $4-6 \mathrm{~h}$ after delivery as in controls, indicating a concomitant development of hepatic glucose production. The rapid postnatal mobilization of hepatic glycogen stores in control newborns

Table 1. Effect of guinea pig normal or anti-insulin serum injection at delivery on plasma glucose and hepatic glycogen concentrations $2 \mathrm{~h}$ after delivery*

\begin{tabular}{lcc}
\hline & $\begin{array}{c}\text { Plasma glucose } \\
(\mathrm{mM})\end{array}$ & $\begin{array}{c}\text { Hepatic glycogen } \\
(\mathrm{mg} / \mathrm{g})\end{array}$ \\
\hline $\begin{array}{l}\text { Control newborns } \\
\text { At delivery }\end{array}$ & $3.08 \pm 0.17(20)$ & $85 \pm 5(20)$ \\
2 h postpartum & $1.68 \pm 0.34(10)$ & $61 \pm 7(10)$ \\
$\quad$ Normal serum & & \\
$\quad$ Anti-insulin serum & $4.82 \pm 0.56(9) \dagger$ & $37 \pm 6(10) \dagger$ \\
Newborns from SH rats & & \\
$\quad$ At delivery & $9.63 \pm 0.61(25) \ddagger$ & $105 \pm 9(25) \S$ \\
2 h postpartum & & \\
$\quad$ Normal serum & $1.06 \pm 0.28(12) \|$ & $98 \pm 11(12)$ \\
$\quad$ Anti-insulin serum & $5.04 \pm 0.55(10) \dagger$ & $40 \pm 5(10) \dagger$ \\
\hline
\end{tabular}

* Data are presented as means \pm SEM. The number of observations is in parentheses.

$\dagger p<0.001$. Significant difference between normal serum-treated and anti-insulin serum-treated newborns.

$\ddagger p<0.001$. Significantly different from controls.

$\S p<0.05$. Significantly different from controls.

$\| p<0.01$. Significantly different from controls. 
argues, as suggested by previous studies $(1,2,18,19)$, for a main role for postnatal glycogen breakdown in restoring euglycemia rapidly after delivery. By contrast, in newborns from $\mathrm{SH}$ rats, the rise of glycemia from $2 \mathrm{~h}$ after delivery cannot be explained by this process because hepatic glycogen concentration, which was very high at delivery, as in other studies $(20,21)$, remained very high during the early postnatal period and failed to significantly decrease from 0 to $8 \mathrm{~h}$ after delivery. We have previously shown that hepatic gluconeogenesis developed prematurely in newborn rats from hyperglycemic mothers and contributed in large part to the restoration of euglycemia by $4-6 \mathrm{~h}$ after birth (5).

When these data are taken together, the time course of plasma glucose concentration during the 16 postnatal $h$ in newborns from $\mathrm{SH}$ and control rats can be explained in the following way: in control newborns, rapid and sustained hepatic glycogenolysis allows near-euglycemia until 8-10 h postpartum. Afterwards, the sharp decrease of plasma glucose concentration is related to the exhaustion of liver glycogen stores that cannot be compensated for by hepatic gluconeogenesis, which is deficient in the fasting newborn rat $(22,23)$. In newborns from $\mathrm{SH}$ rats, sparing of liver glycogen stores due to faulty early glycogenolysis and the delayed initiation of glycogen breakdown are likely responsible for the absence of a significant decrease of plasma glucose concentration between 10 and $16 \mathrm{~h}$ postpartum.

Role of insulin and glucagon in initiation of liver glycogen breakdown. The fall in the insulin/glucagon molar ratio, which was observed during the early postnatal period in the newborn rat in many previous studies (reviewed in 14), as well as in the present one, is supposed to play the main role in glycogen breakdown triggering (reviewed in 19). Previous studies have shown that when the insulin/glucagon molar ratio was abnormally high in full-term rats and when its postnatal decrease was prevented, such as in offspring of slightly hyperglycemic (5) or mildly diabetic rats (24), postnatal glycogen breakdown was impaired $(5,24)$. However, under these conditions, the insufficient decrease of insulin/glucagon ratio resulted from both persistent hyperinsulinemia and the lack of increase of plasma glucagon concentration. Therefore, it was very difficult to determine the respective importance of the two hormones. In our study, several lines of evidence indicate that high plasma insulin levels at delivery and during the early postnatal period impair hepatic glycogenolysis. The first evidence is provided by the fact that in newborns from $\mathrm{HH}$ rats, which were normoinsulinemic, hepatic glycogen concentration was rapidly decreased after delivery and reached values similar to those in controls from $8 \mathrm{~h}$ onward, despite the fact that plasma glucose levels remained higher and plasma glucagon remained lower than in controls until $10 \mathrm{~h}$ postpartum. The crucial role played by hyperinsulinemia in preventing glycogen breakdown is also supported by the ability of anti-insulin serum injected at delivery to promote a prompt decrease in liver glycogen concentration, not only in control newborns, as in previous studies (25), but also in newborns of $\mathrm{SH}$ rats.

Note that, in newborns from $\mathrm{HH}$ rats, hepatic glycogen concentration, although significantly decreased compared with newborns from $\mathrm{SH}$ rats, remained higher than in controls until $6 \mathrm{~h}$ after delivery. This situation is probably related to the concomitant high plasma glucose concentration exhibited by newborns from $\mathrm{HH}$ rats. It is well known that glucose may influence hepatic glycogen metabolism independently of its ability to stimulate insulin secretion and, especially via its inhibitory effect on phosphorylase activity, in the absence of a significant change of insulin concentration (reviewed in 26).

Enzymes of glycogen metabolism. Glycogen synthase and glycogen phosphorylase are the two rate-limiting enzymes of glycogen metabolism. Both enzymes exist in active (synthase a and phosphorylase a) and inactive (synthase $b$ and phosphorylase $b$ ) forms. Many studies on the control of glycogen metabolism in the liver have indicated that the rates of glycogen synthesis and degradation are proportional to the concentration of active glycogen synthase and active glycogen phosphorylase, respectively $(27,28)$. Insulin and glucagon are the main hormones involved in regulation of synthase and phosphorylase activities in the adult as well as in the fetal and newborn rat liver $(29,30)$. In our study, the time course of liver glycogen concentration after delivery was fitted rather well to the evolution of the activities of both enzymes. Phosphorylase a/synthase a ratio was lower at delivery than during the postnatal period in all groups of newborns in relation with high hepatic glycogen concentrations. However, at this time, glycogen phosphorylase activity was already higher than glycogen synthase activity, in accordance with previous observations that showed that immediately before parturition, glycogen synthase activity normally declines and glycogen phosphorylase rapidly increases $(21,31)$. In newborns from control and, to a lesser extent, $\mathrm{HH}$ rats, phosphorylase a/synthase a ratio rose rapidly after delivery to reach a maximum at $4 \mathrm{~h}$ that corresponds to the higher rate of glycogen degradation. By contrast, in newborns from SH rats, it rose much more slowly than in the two other groups and was at its maximum at $16 \mathrm{~h}$, corresponding to delayed glycogenolysis in these newborns.

In conclusion, hyperinsulinemia during late fetal and very early neonatal life seems to be per se responsible for impaired postnatal glycogenolysis in newborns from SH mothers. Our data also suggest that a significant fall in plasma insulin concentration might be an absolute requirement for glycogen breakdown triggering in the newborn, whatever the level of the glycogenolytic "stimulus" (high plasma glucagon and low plasma glucose concentrations).

Acknowledgments. The authors thank Dr. G. Rosselin and C. Gespach, INSERM U55, for the gift of iodinated insulin and insulin antibody. We thank also M. F. Berthault for her expert technical assistance.

\section{REFERENCES}

1. Girard JR, Cuendet GS, Marliss EB, Kervran A, Rieutort M, Assan R 1973 Fuels, hormones and liver metabolism at term and during the early postnatal period in the rat. J Clin Invest 52:3190-3200

2. Shelley HJ, Bassett JM, Milner DG 1979 Control of carbohydrate metabolism in the fetus and newborn. Br Med Bull 31:37-43

3. Exton JH, Park CR 1972 Interaction of insulin and glucagon in the control of liver metabolism. In: Handbook of Physiology. American Physiological Society, Washington, DC

4. Kahlan SC, Savin SM, Adam PAJ 1976 Measurement of glucose turn-over in the human newborn with glucose ${ }^{14} \mathrm{C}$. $\mathrm{J}$ Clin Endocrinol Metab 43:704-707

5. Nurjhan N, Ktorza A, Ferré P, Girard J, Picon L 1985 Effects of gestational hyperglycemia on glucose metabolism and its hormonal control in the fasted, newborn rat during the early postnatal period. Diabetes 34:995-1001

6. Kervran A, Guillaume M, Jost A 1978 The endocrine pancreas of the fotus from diabetic pregnant rat. Diabetologia 15:387-393

7. Bihoreau MT, Ktorza A, Kervran A, Picon L 1986 Effect of gestational hyperglycemia on insulin secretion in vivo and in vitro by fetal rat pancreas. Am J Physiol 251:E1-E6

8. Eriksson U, Andersson A, Efendic S, Elder R, Hellerström C 1980 Diabetes in pregnancy: effects on the fotal and newborn rat with particular regard to body weight, serum insulin concentration and pancreatic content of insulin, glucagon and somatostatin. Acta Endocrinol (Copenh) 94:354-364

9. Ktorza A, Girard J, Kinebanyan MF, Picon L 1981 Hyperglycemia induced by glucose infusion in unrestrained pregnant rat during the last 3 days of gestation: metabolic and hormonal changes in the mother and the fetus. Diabetologia 21:569-574

10. Nicolaïdis S, Rowland N, Meile MJ, Marfaing-Jallat P, Pesez A 1974 A flexible technique for long term infusions in unrestrained rats. Pharmacol Biochem Behav 2:131-136

11. Roehrig KL, Allred JB 1974 Direct enzymatic procedure for the determination of liver glycogen. Anal Biochem 58:414-421

12. Hue L, Bontemps F, Hers HG 1975 The effect of glucose and of potassium ions on the interconversion of the two forms of glycogen phosphorylase and of glycogen synthetase in isolated rat liver preparations. Biochem $\mathrm{J} 206: 1-$ 12

13. Stalmans W, De Wulf H, Hers HG 1974 The sequential inactivation of glycogen phosphorylase and activation of glycogen synthase in liver after the administration of glucose to mice and rats. Eur J Biochem 41:127-134

14. Ktorza A, Bihoreau MT, Nurjhan N, Picon L, Girard J 1985 Insulin and glucagon during the perinatal period: secretion and metabolic effects on the liver. Biol Neonate 48:204-220 
15. Bloom SR, Johnston DI 1972 Failure of glucagon release in infants of diabetic mothers. Br Med J 4:453-454

16. Williams PR, Sperling MA, Racasa Z 1979 Blunting of spontaneous and alanine-stimulated glucagon secretion in newborn infants of diabetic mothers. Am J Obstet Gynecol 133:51-56

17. Grasso S, Falluca D, Mazzone L, Giangrande L, Romea G, Reitano G 1983 Inhibition of glucagon secretion in the human newborn by glucose infusion. Diabetes 32:489-492

18. Jost $A$, Jacquot $R 1958$ Sur le contrôle de l'hypophyse, des surrénales et du placenta dans la synthèse du glycogène dans le foie fortal de lapin et de rat. C R Hebd Seances Acad Sci 247:2459-2462

19. Girard JR 1981 Glucose homeostasis in the perinatal period: the critical role of pancreatic hormones and exogenous substrates in the rat. Ciba Found Symp 86:234-246

20. Gilbert M, Bourbon $J 1978$ Turnover of liver glycogen in the rat foetus. Biochem J $176: 785-789$

21. Singh M, Feigelson M 1981 Effects of maternal diabetes on the development of carbohydrate metabolizing enzymes in fetal rat liver. Arch Biochem Biophys 209:655-677

22. Girard J, Guillet I, Marty J, Marliss EB 1975 Plasma amino acid levels and development of hepatic gluconeogenesis in the newborn rat. Am J Physiol 229:E466-E473
23. Ferré P, Pégorier JP, Marliss EB, Girard JR 1978 Influence of exogenous fat and gluconeogenic substrates on glucose homeostasis in the newborn rat. Am J Physiol 234:E129-E136

24. Cuezva JM, Burkett ES, Kerr DS, Rodman HM, Patel MS 1982 The newborn of diabetic rat. I: Hormonal and metabolic changes in postnatal period. Pediatr Res 16:632-637

25. Snell K, Walker DG 1980 Glucose metabolism in the newborn rat: the role of insulin. Diabetologia 14:59-64

26. Hers HG 1981 Non-hormonal control of glycogen synthesis. In: Hue L, Van De Werve G (eds) Short-Term Regulation of Liver Metabolism. Elsevier/ North-Holland Biochemical Press, New York, pp 105-116

27. Watts C, Gain KR 1976 Glycogen metabolism in the liver of the developing rat. Biochem J 160:263-270

28. Devos P, Hers HG 1974 Glycogen metabolism in the liver of the fœetal rat. Biochem J 140:331-340

29. Margolis RN 1983 Regulation of hepatic glycogen metabolism in pre- and postnatal rats. Endocrinology 113:893-902

30. Van De Werve G, Jeanrenaud B 1987 Liver glycogen metabolism: an overview. Diabetes Metab Rev 3:47-78

31. Margolis N, Seminara D 1988 Glycogen metabolism in late gestation in fetuses of maternal diabetic rats. Biol Neonate 54:133-143 